\title{
Sonographic Assessment of the Umbilical Cord
}

\author{
Sonografie der Nabelschnur
}

Authors

Affiliations
S. Bosselmann ${ }^{1,2}$, G. Mielke ${ }^{2}$

${ }^{1}$ Frauenklinik, Universitätsklinikum Heidelberg, Heidelberg

2 Pränatalzentrum Stuttgart, Stuttgart

\section{Key words \\ - ultrasound \\ - fetal period \\ - umbilical cord \\ Schlüsselwörter \\ - Ultraschall \\ - Fetalzeit \\ - Nabelschnur}

Deutschsprachige

Zusatzinformation unter: www.thieme-connect.de/ ejournals/gebfra

\section{Abstract \\ $\nabla$}

The umbilical cord (UC) is a vital connection between fetus and placenta. It constitutes a stable connection to the fetomaternal interface, while allowing the fetal mobility that is of great importance for fetal development in general and fetal neuromotor development in particular. This combination of mechanical stability and flexibility is due to the architecture of the UC. There is however a range of umbilical cord complications that may be life threatening to the fetus and these too can be explained to a large extent by the cord's structural characteristics. This review article discusses clinically relevant aspects of UC ultrasound.

\section{Zusammenfassung \\ $\nabla$}

Die Nabelschnur ist die lebenswichtige Verbindung zwischen Fetus und Plazenta. Sie bildet einerseits eine stabile Verbindung zur zentralen Einheit des fetomaternalen Stoffwechsels und ermöglicht dem Feten andererseits eine Beweglichkeit, die für die körperliche - insbesondere die neuromotorische - Entwicklung von großer Bedeutung ist. Diese Kombination aus mechanischer Stabilität und Flexibilität begründet sich in der Architektur der Nabelschnur. Es gibt jedoch eine Reihe an Nabelschnurkomplikationen, die den Feten z.T. lebensbedrohlich gefährden können. Auch diese lassen sich vor allem auf die strukturellen Eigenschaften der Nabelschnur zurückführen. Im Rahmen einer Übersichtsarbeit werden klinisch relevante Aspekte der sonografischen Diagnostik der Nabelschnur besprochen.

Introduction

The umbilical cord (UC) is the essential life-sustaining connection between fetus and placenta. It constitutes a stable connection to the fetomaternal interface, while allowing fetal mobility that is essential for fetal development in general and neuromotor development in particular. This combination of mechanical stability and flexibility is due to the architecture of the UC. There is however a range of umbilical cord complications that may be life threatening to the fetus, and these too can be explained to a large extent by the cord's structural characteristics. Examination of cord vessels using Doppler ultrasound enables investigators to deduce the state of the fetoplacental vascular bed, providing essential information on the condition of the fetus.

\section{Dr. Stephan Bosselmann}

Universitätsklinikum Heidelberg Frauenklinik

Im Neuenheimer Feld 440

69120 Heidelberg

Stephan.Bosselmann@

med.uni-heidelberg.de

\section{Development and Architecture of the Umbilical Cord \\ $\nabla$}

In its embryonic stage the UC develops in the region of the body stalk to become the embryo's connection to the fetal portion of the placenta (fetal placenta). The amniotic cavity expands from dorsal to ventral while the chorionic cavity shrinks in volume. During cephalo-caudal and lateral folding the early UC arises as it is "enveloped" by the expanding amnion ( $\bullet$ Fig. 1 ) (see also textbooks of embryology, www.embryology.ch). In this early stage at around 7-8 weeks postmenstrual age the UC contains the body stalk with umbilical vessels as well as other structures that will later regress and disappear entirely: the allantoic diverticulum (an outpouching from the endoderm connected to the (future) urinary bladder, later the urachus), as well as the extra-embryonic coelom that at this early stage still forms a connection to the cho- 


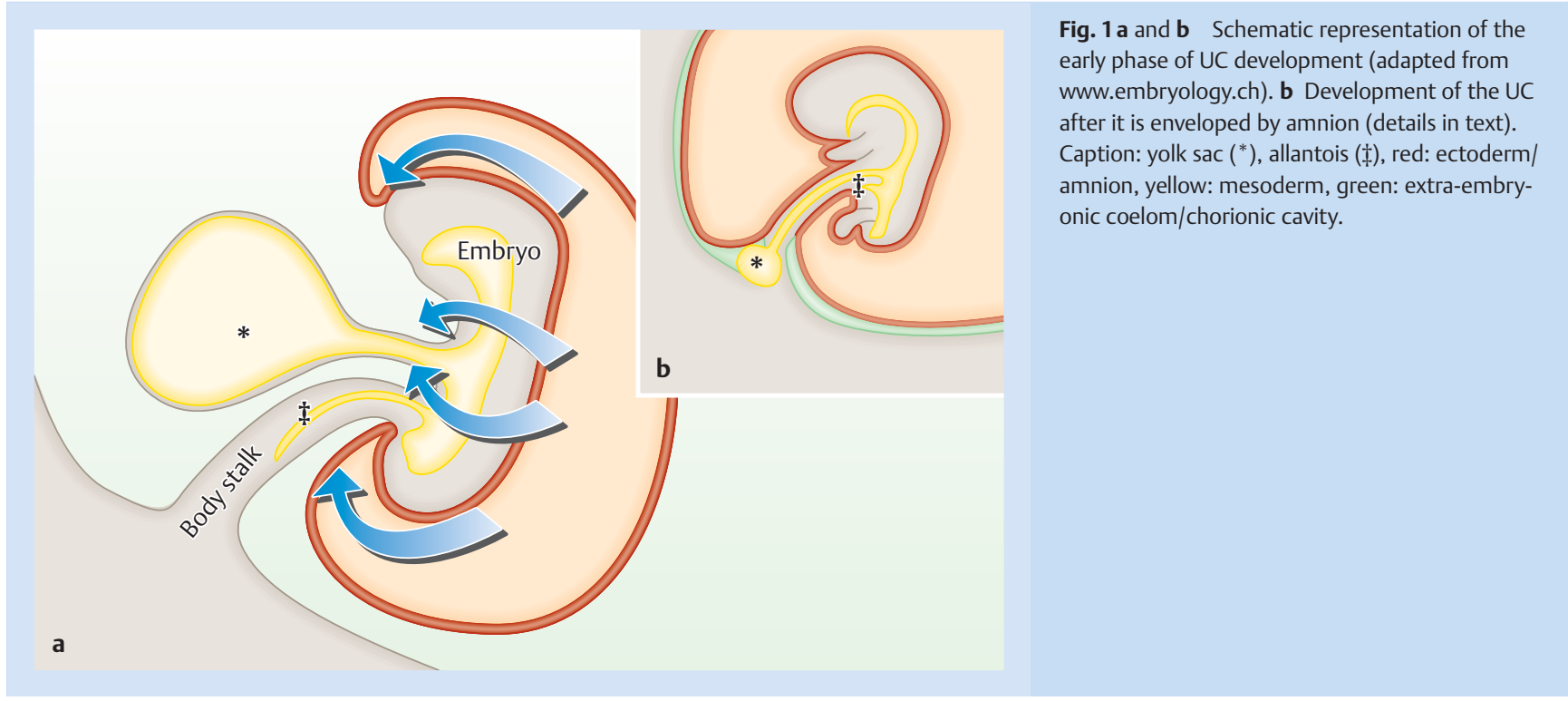

rionic cavity and contains the omphaloenteric duct (connected to the yolk sac).

There are initially four umbilical vessels: two arteries (UA) and two veins (UV). Typically the right UV subsequently atrophies, thus forming the usual three-vessel umbilical cord with one vein carrying oxygenated blood to the fetus and two arteries carrying fetal blood in the opposite direction to the placenta (the vessels are designated as arteries or veins according to their relationship to the fetal heart, not the oxygen content of the blood they carry). Despite being extremely flexible the UC possesses a mechanical stability that protects its vessels from compression, kinking and rupture. Important contributors to this stability are the cord's outer layer formed by the amnion (amniotic epithelium) and socalled Wharton's jelly, the connective tissue of the UC with extracellular matrix. The amnion protects the umbilical vessels from tensile forces. Protection from compression is, however, even more important. The extracellular matrix of Wharton's jelly (e.g. proteoglycans, hyaluronic acid) is hydrophilic and has a highly viscous, jelly-like consistency [1]. In addition collagen fibers are arranged concentrically around the cord vessels. Local pressure is thus cushioned, and the danger of umbilical vessel occlusion, for example caused by normal fetal movement, is significantly reduced. Normal values for UC diameter and cross-sectional area for gestational age have been established. They increase up until the 32nd week of pregnancy and correlate with fetal biometrics as well as the content of Wharton's jelly [2].

Both umbilical arteries are functionally part of the same segment of fetoplacental circulation. They share a close anatomical relationship within the UC, their lumens being connected by the Hyrtl anastomosis. Named after Josef Hyrtl who first described it, this anastomosis is usually located within the last $3 \mathrm{~cm}$ of the cord before its placental insertion and serves to compensate pressure and volume differences in the placental circulation further downstream [3]. This pressure regulation mechanism appears to be of particular importance during uterine contractions. Differences in caliber and resistance in both UAs have been described in association with cord insertion pathologies (see below) and absence of the Hyrtl anastomosis [4]. Anatomical variants of the Hyrtl anastomosis have been described in association with hypertensive disorders of pregnancy. The Hyrtl anastomosis can be demonstrated antenatally $[5,6]$.

The UAs wrap themselves around the UV to various degrees. The umbilical coiling index, described by Strong et al. in 1994 [7], denotes the number of complete turns (coils) the UAs make per centimeter of umbilical cord length. Normal values are between $0.3-$ 0.5 coils $/ \mathrm{cm}$, though values decline with increasing gestational age [8-10]. Adverse outcomes have been described for both "hypercoiling" (IUGR, pathological fetal heart rate during contractions, low birth weight, thrombosis and stenosis of vessels) and "hypocoiling" (oligohydramnios, pathological fetal heart rate during delivery, low birth weight, operative vaginal delivery, intrauterine death) $[8,11]$; nevertheless, both a systematic review as well as the author's own large, low-risk cohort have shown no association with neonatal outcome [12]. Likewise, conflicting data exist on the association with chromosomal anomalies [10]. Cord biometrics, the coiling index and examination of the Hyrtl anastomosis are currently not part of routine antenatal examination of the UC. The main clinically relevant parameters include the cord's length, the configuration at both ends and the characteristics of individual cord vessels.

Ultrasound examination of the UC and its clinical aspects according to gestational age at diagnosis is discussed in detail below.

\section{The First Trimester}

\section{$\nabla$}

\section{Umbilical cord length, body stalk anomaly}

Umbilical cord length varies, with a range of $35-70 \mathrm{~cm}$ at birth being regarded as normal. Both shorter and longer cords are associated with increased rates of intrapartum complications [13]. UC length is thus a significant factor when assessing fetal risk. Antenatal estimation of cord length is however extremely difficult. Traction force produced by fetal movements in the first trimester is assumed to be the crucial growth stimulus of the cord [14]. A short UC is thus associated with reduced fetal movement and all its respective causes (e.g. malformation, myopathies, neuropathies, oligohydramnios).

The body stalk anomaly, with an incidence between 1:7500$1: 31000$ depending on gestational age at diagnosis, refers to a 

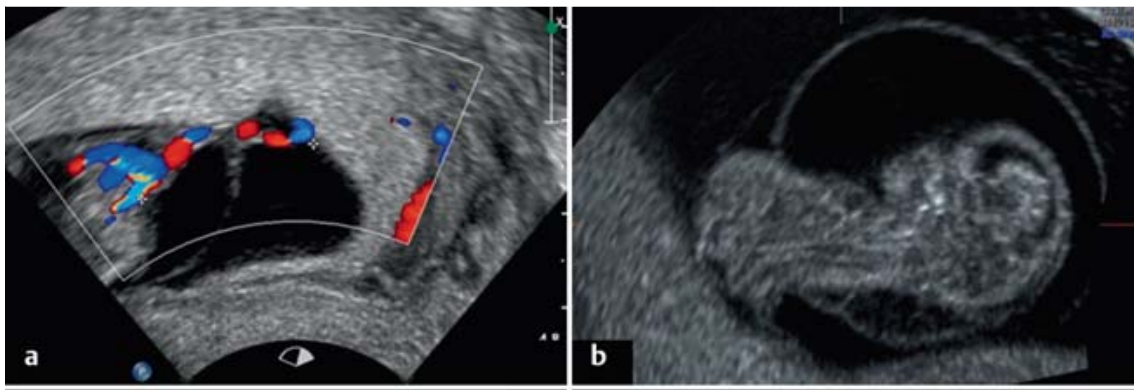

Fig. $\mathbf{2}$ a to $\mathbf{d}$ Ultrasound findings in the body stalk anomaly.

a Short umbilical cord.

b Partial extraamniotic position of the fetus: the upper body is surrounded by the circular depicted amnion, while the lower body lies outside of the amnion.

c $3 \mathrm{D}$ surface image of the same fetus as in $\mathbf{b}$.

A large abdominal wall defect is visible with herniation of liver $(\rightarrow)$ and intestine $\left({ }^{*}\right)$. The amnion can also be seen $(\triangleright)$ - it extends up to the abdominal wall defect.
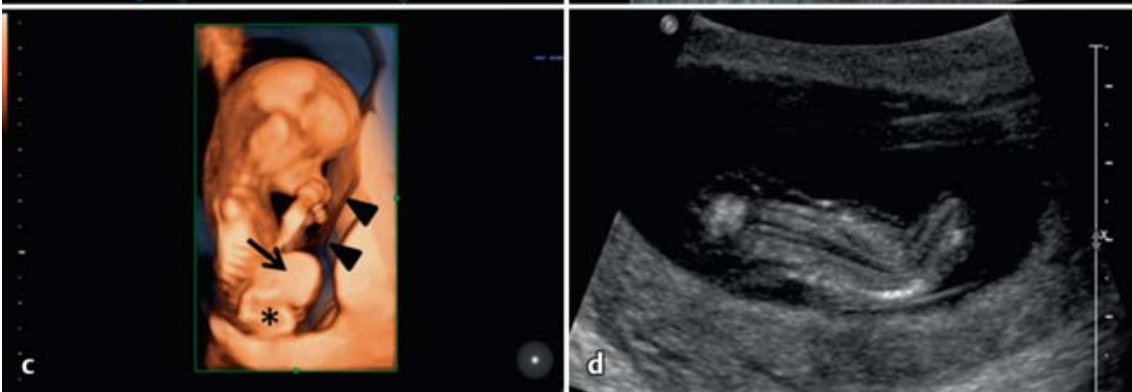

d Scoliosis in a different fetus with body stalk anomaly.

particularly short UC associated with a high spontaneous abortion rate [15]. It can be detected by ultrasound as early as the first trimester ( $\odot$ Fig. 2). It is characterised by multiple congenital anomalies including abdominal wall defect, absent or extremely short UC with possible single UA and direct attachment of the fetus to the placenta, and lower limb deformities. The term "limb bodywall complex" (LBWC), which is also used in literature, is probably best considered as a variant of the body stalk anomaly [16]. Body stalk anomaly quite commonly presents with fetal spinal deformity (kyphoscoliosis) and cranial defects as additional findings. Nuchal translucency and alpha-fetoprotein (AFP) in maternal serum are typically increased, while fetal karyotype is usually normal [17]. Anomalous development of the body stalk causes the syndrome, which explains the typical location of the lower limbs and abdominal organs in the extraembryonic coelom (chorionic cavity). The upper half of the fetus is located within the amniotic cavity. Some authors compare the pathology to an extreme form of amniotic band sequence, although various theories on its pathogenesis exist.

The differential diagnosis includes other syndromes associated with ventral body wall defects ( $\bullet$ Table 1 ).

Prognosis depends on the severity of the various abnormalities and is very poor to infaust [17].

Longer than average umbilical cords are associated with increased risk of UC loops, knots and cord prolapse. These complications are of greater clinical importance in the third trimester and will be discussed later.

\section{Fetal and placental insertion of the umbilical cord}

The ends of the UC are usually easy to demonstrate by ultrasound in the first trimester, given the relative abundance of space in utero at this stage. As gestational age increases, however, visualisation becomes increasingly difficult and may be impossible, especially when the placenta is posterior. Both ends of the UC may show abnormalities that have an impact on the subsequent management of pregnancy.

\section{Placental umbilical cord insertion}

In addition to the "normal" central and paracentral umbilical cord attachments, insertion anomalies with more peripheral
Table 1 Differential diagnosis of abdominal wall defects.

\begin{tabular}{|ll|}
\hline $\begin{array}{l}\text { Syndrome } \\
\text { Body stalk } \\
\text { anomaly }\end{array}$ & $\begin{array}{l}\text { Structural abnormalities } \\
\text { Ventral clefts, short or absent umbilical cord, fetal } \\
\text { position partially in extraembryonic coelom, with or } \\
\text { without other malformations (cranial, vertebral) }\end{array}$ \\
\hline $\begin{array}{l}\text { Limb Body Wall } \\
\text { Complex }\end{array}$ & As above with lower limb abnormalities \\
\hline $\begin{array}{l}\text { Pentalogy of } \\
\text { Cantrell }\end{array}$ & $\begin{array}{l}\text { Abdominal wall defects (omphalocele), lower sternal } \\
\text { defect/cleft, anterior diaphragmatic hernia, pericardial } \\
\text { defect/ectopia cordis, cardiovascular malformations }\end{array}$ \\
\hline OEIS complex & $\begin{array}{l}\text { Omphalocele, bladder extrophy, imperforate anus, } \\
\text { caudal neural tube defects (spina bifida) }\end{array}$ \\
\hline Gastroschisis & $\begin{array}{l}\text { Defect usually to the right of the umbilicus, UC insertion } \\
\text { normal, intestinal loops float freely in the amniotic cavity. }\end{array}$ \\
\hline Omphalocele & $\begin{array}{l}\text { Defect at the umbilicus, parietal peritoneum forms } \\
\text { hernial sac, various herniated abdominal organs. }\end{array}$ \\
\hline $\begin{array}{l}\text { Bladder or cloa- } \\
\text { cal extrophy }\end{array}$ & $\begin{array}{l}\text { Bladder undetected on ultrasound, normal amount } \\
\text { of amniotic fluid, low umbilical cord attachment }\end{array}$ \\
\hline
\end{tabular}

cord attachment occur. A cord insertion of less than $2 \mathrm{~cm}$ from the edge of the placenta is clinically significant. In marginal cord insertion (5-7\% of pregnancies) the UC arises directly from the edge of the placenta $[11,18]$. Anomalous cord insertion is associated with an increased rate of intrauterine growth restriction so that fetal monitoring should be intensified if it is detected antenatally [19]. The UC insertion can be found sonographically using colour Doppler by following the chorionic plate vessels. If demonstration of the cord insertion is no longer possible, which may be the case as gestation advances, tangential visualisation of the placental surface may be helpful to obtain an overview ( Fig. 3). Using this technique the chorionic plate vessels can be demonstrated by colour Doppler as they approach the UC insertion, creating a star-like pattern.

It is particularly important to diagnose velamentous cord insertion, a pathological insertion of the cord seen in $1-2 \%$ of pregnancies [11]. Here the origin of the actual UC lies outside the placenta ( Fig. 4a) and consists of velamentous vessels (enveloped $\rightarrow$ here: between the amniotic membranes i.e. between 

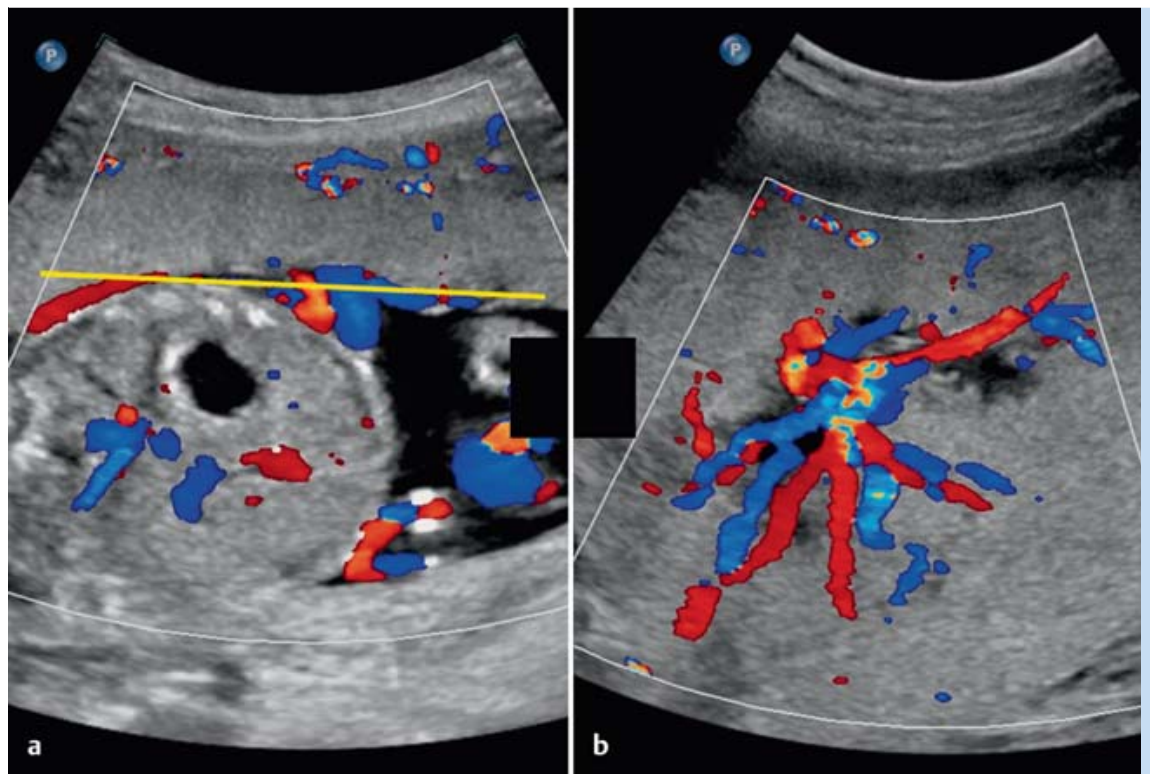

Fig. $3 \mathbf{a}$ and $\mathbf{b}$ Normal umbilical cord insertion. a Demonstration of the cord insertion and a number of chorionic plate vessels. Depending on fetal lie visualisation may be difficult even if the placenta is anterior. For further differentiation it may be helpful to examine the placenta tangentially as in $\mathbf{b}$. The star-like pattern of the chorionic plate vessels as they approach the cord insertion is seen. Placental tissue surrounds them. The yellow line in a represents the level and orientation of the image in $\mathbf{b}$.
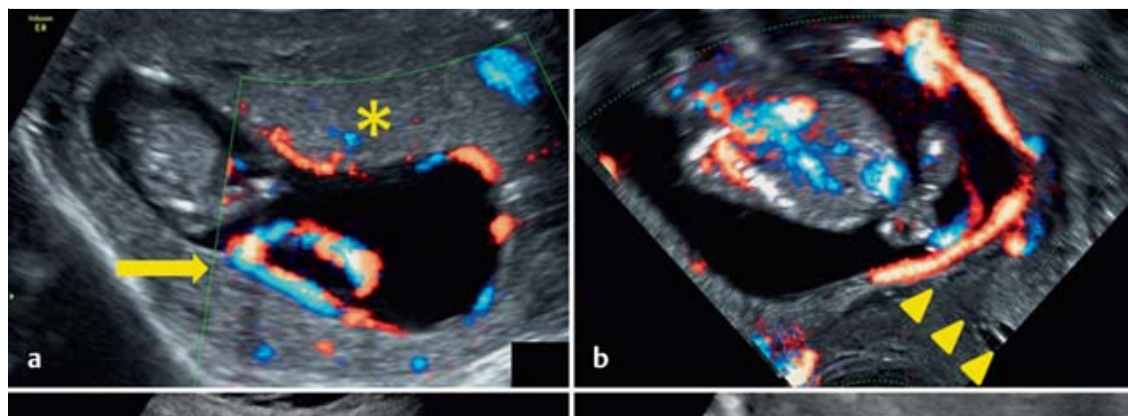

Fig. 4 a to $d$ Pathological cord insertions.

a Velamentous insertion at the end of the first trimester. The UC insertion is demonstrable opposite the chorion frondosum.

b Transvaginal view of the same pregnancy as in a. A velamentous vessel runs directly across the cervical os (^ vasa praevia).

$\mathbf{c}$ and $\mathbf{d}$ Demonstration of velamentous vessels in the second trimester: $\mathbf{c}$ Longitudinal section. d Transverse section. These findings must always
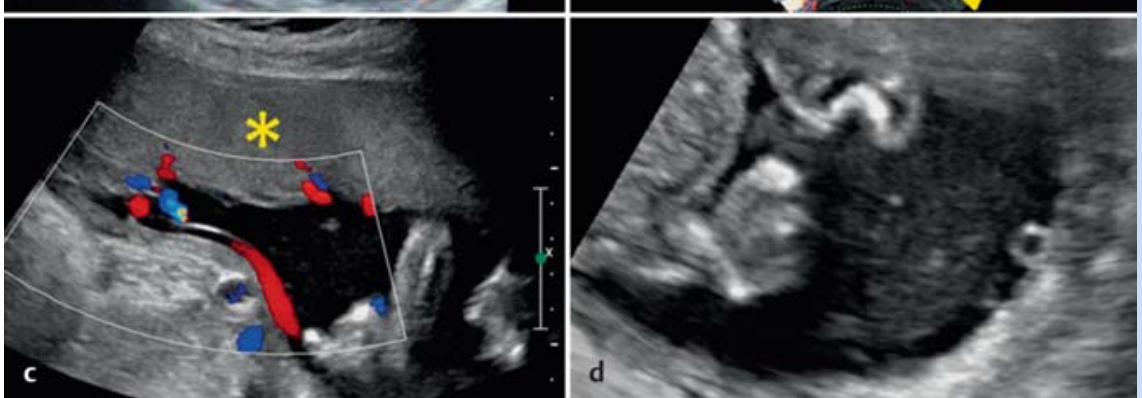
be followed by further assessment of placental UC insertion (to exclude velamentous insertion) and examination of the lower uterine segment (to exclude vasa praevia). Caption: chorion frondosum/ placenta $\left({ }^{*}\right)$; cord insertion $(\rightarrow)$; cervical canal $(\bullet)$.

amnion and chorion). In contrast to normal UC vessels, velamentous vessels are not protected by the stabilising effect of Wharton's jelly. There is an increased risk of cord compression, fetal growth restriction, premature labour, placental abruption, CTG abnormalities and low Apgar scores [11]. It is important to be aware that velamentous cord insertion is associated with an increased rate of vasa praevia.

The term vasa praevia describes velamentous vessels that lie in direct proximity to the cervix and below the fetal "presenting part" ( Figs. 4 b and d); the prevalence of this anomaly is $0.04 \%$ [20]. Risk factors for vasa praevia, apart from velamentous cord insertion (vasa praevia type I), include accessory placenta (vasa praevia type II) [21], and multiple pregnancy and pregnancy in the setting of assisted reproduction [22]. The closer the vessels are to the internal os (which exposes them to traction and shearing forces during birthing efforts, especially in the context of premature rupture of membranes) the greater the danger of vessel rupture and massive fetal haemorrhage. Prenatal diagnosis of va- sa praevia followed by delivery by primary caesarean section prior to the onset of labour can increase survival from 44 to $97 \%$ [20]. Depending on gestational age RDS prophylaxis should be considered since increased rates of preterm delivery are probable $[21,23]$. A current systematic review describes antenatal detection rates of vasa praevia of between 53 and 100\% [24]. Transvaginal colour Doppler ultrasound is best for diagnosis. Detection rates may be much lower in the abdominal plane. According to a screening algorithm proposed by Rebarber et al. transvaginal ultrasound should be performed in every pregnant woman who presents with any of the following criteria [25]:

- Placenta praevia in the current pregnancy that is subsequently no longer demonstrable

- Vasa praevia in a previous pregnancy

- Velamentous cord insertion in the lower uterine segment

- Accessory placenta in the lower uterine segment

- Multiple pregnancy 

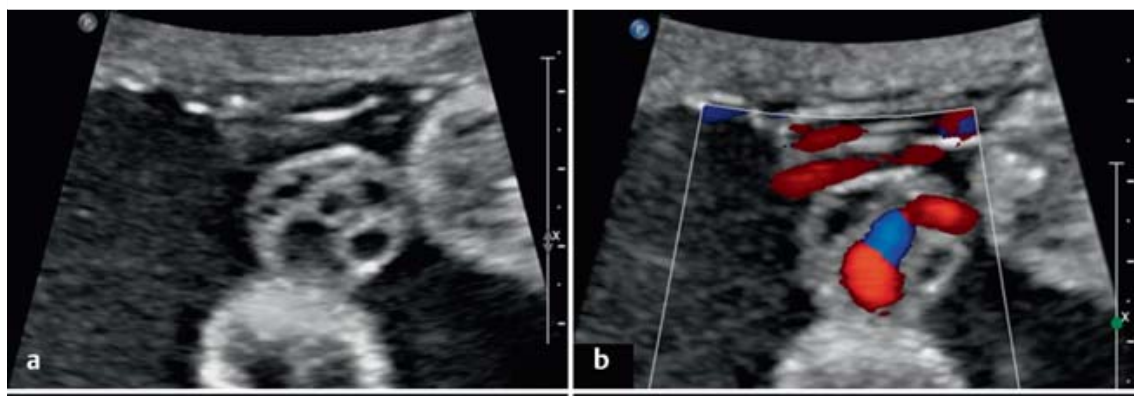

Fig. $\mathbf{5}$ a to $\mathbf{d}$ Cystic segment of UC in cross section ( $\mathbf{a}$ und $\mathbf{b}$ ), and in longitudinal section ( $\mathbf{c}$ und $\mathbf{d}$ ). Cysts can be differentiated from perfused vessels using Doppler ultrasound (b und d). Despite the cysts' segmental occurrence and irregular shape, both characteristic of pseudocysts, differentiation is only possible on histology. This fetus also had agenesis of the septum pellucidum, schizencephaly and atrioventricular valve incompetence.
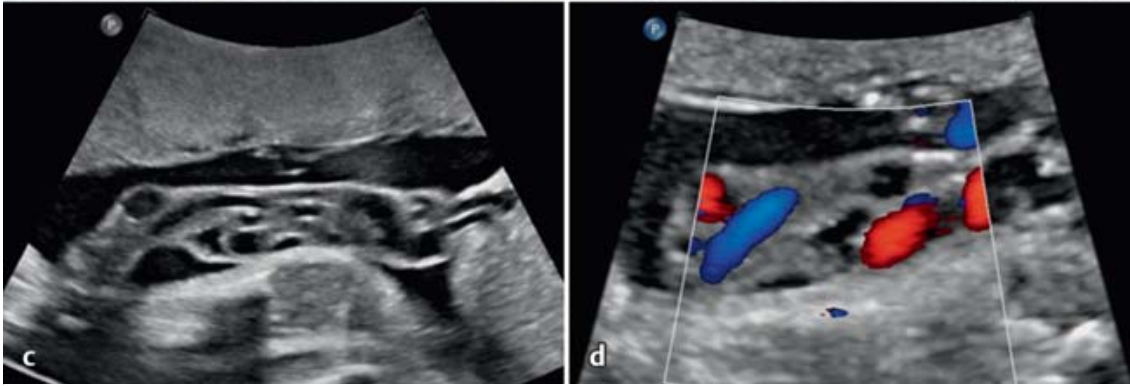

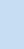
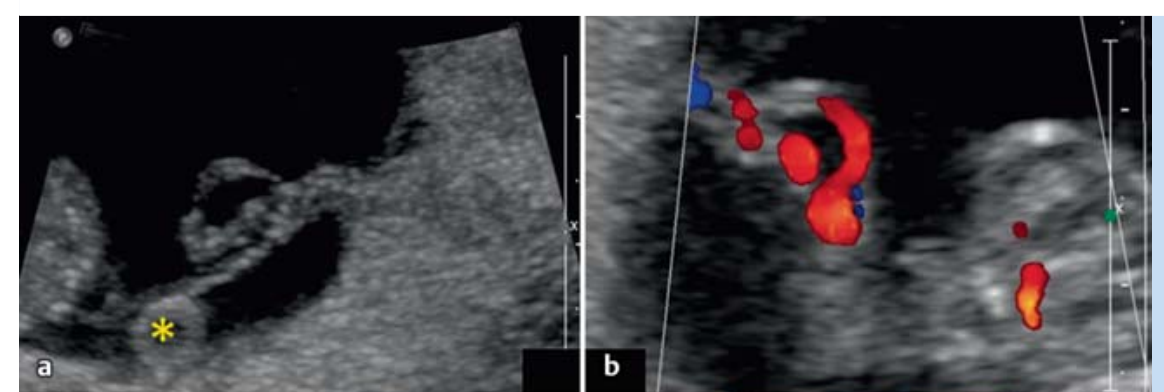

\section{Fig. 6 a to $d$}

$\mathbf{a}$ and $\mathbf{b}$ Demonstration of an UC cyst in a central cord segment in the first trimester;

c and d Fetus with a large UC cyst located at the fetal cord insertion. The echogenic appearance of the cyst margin nearest the abdominal wall $(\triangleright)$ raises the suspicion of an abdominal wall defect. An omphalocele was subsequently diagnosed. Caption: yolk sac $\left({ }^{*}\right)$.
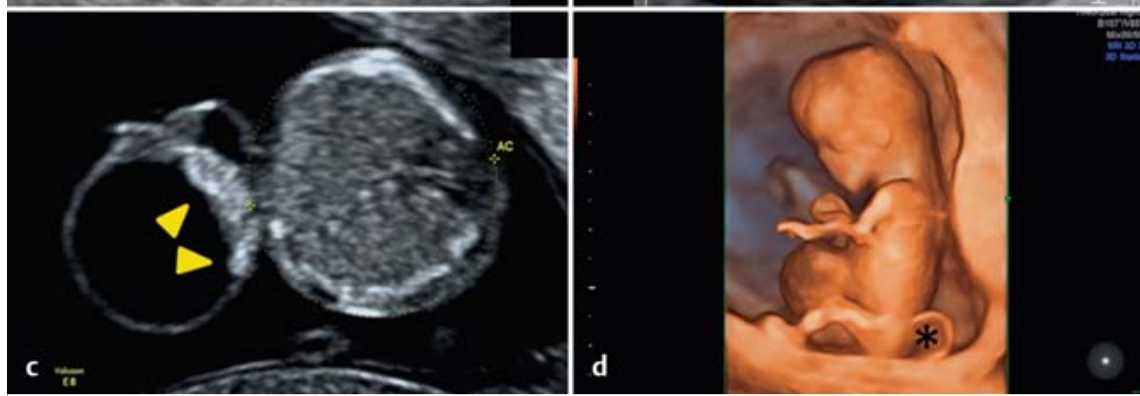

In a large cohort of patients ( $\mathrm{n}=27573$ with 31 cases of vasa praevia) the authors showed that when diagnosis was made before 26 weeks gestation, vasa praevia was subsequently no longer demonstrable in $24 \%$ of cases, whereas if diagnosis was made in the third trimester it persisted.

\section{Fetal umbilical cord insertion}

Abnormalities of cord attachment can also occur on the fetal side. Abdominal wall defects at the UC insertion (gastroschisis and omphalocele) are the most important. The incidence of both entities is around 3:10000 although that of gastroschisis has increased in recent years for reasons as yet unknown [16]. Omphalocele must be differentiated from physiological umbilical hernia that occurs in the first trimester during intestinal rotation and normally regresses before the 12th week. The UC and its fetal insertion are anatomical landmarks, important criteria to be visualised to differentiate abdominal wall defects. Omphalocele occurs at the umbilicus. The defect is covered by peritoneum with the UC inserting into this hernial sac. The relatively high rate of associated genetic abnormalities is an important aspect requiring consideration. In gastroschisis the UC inserts normally into the abdominal wall, in most cases to the left of the wall defect. The viscera lie freely in the amniotic cavity. While the karyotype is usually normal, the rate of associated abnormalities is approximately $10 \%$ [26]. A detailed discussion is beyond the scope of this text [16].

\section{Umbilical cord cysts}

Cysts can occur anywhere along the entire length of the umbilical cord ( Figs. 5 and 6); the incidence in the first trimester is between 0.4 and $3.4 \%[27,28]$. Histologically they are differentiated according to their origins into either true (epithelialized) cysts or pseudocysts (lacunar expansions/protuberances of Wharton's jelly).

True cysts can occur as remnants of the allantois or the omphaloenteric duct, or as vascular malformations. They may be associ- 

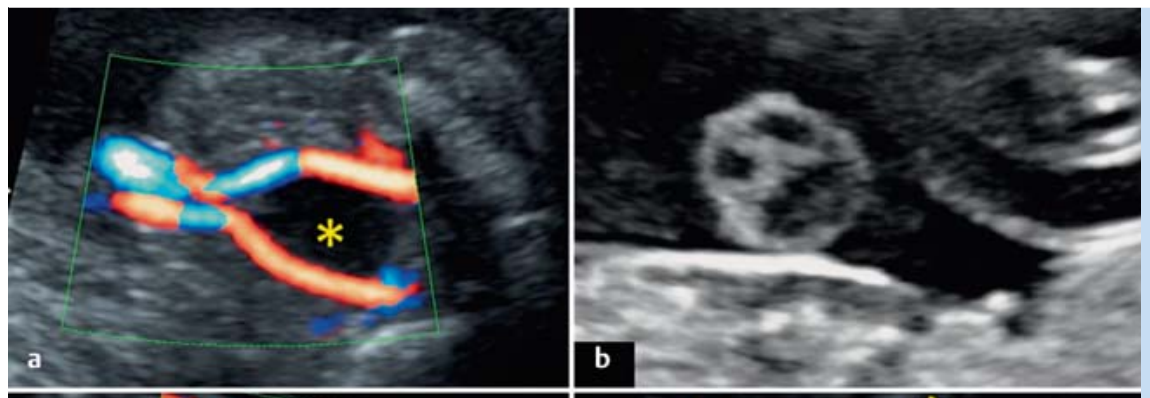

Fig. 7 a to $d$

a Perivesical course of the UAs right up to the fetal cord insertion.

b Cross section of a normal umbilical cord. The three vessel lumens appear as a stylized Mickey Mouse.

c Demonstration of two UAs in their perivesical course in the first trimester up to the fetal cord insertion.
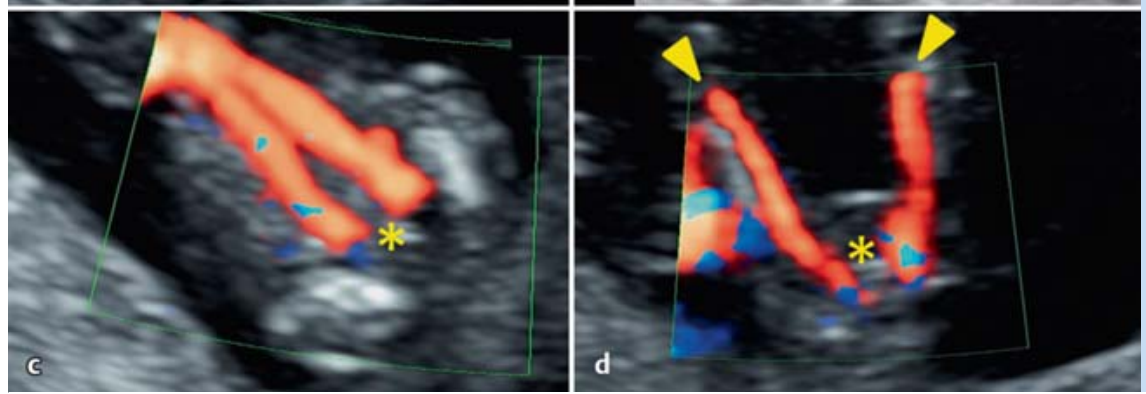

d Due to their close proximity in the first trimester, the UAs may be confused with the femoral arteries $(\triangleright)$. Caption: urinary bladder $\left({ }^{*}\right)$.

ated with malformations (eg. omphalocele, urachus fistula) and chromosomal abnormalities (especially trisomy 18). As most of the available literature on the subject is in the form of case reports and small case series, data on complication rates and clinical course are limited.

Cases of UC cysts should be followed up by detailed investigation for associated malformations. Many first trimester cysts disappear by the second trimester (ca. 80\% [11]), a development associated with a good prognosis [29]. UC cysts in the second and third trimester have a poorer prognosis due to the above-mentioned complications [28].

\section{Number of vessels/single umbilical artery}

Early in its development the umbilical cord is formed from four vessels. At this stage there are two umbilical arteries (UA) and two umbilical veins (UV) of which the right UV typically atrophies by the 6 th week of gestation. Thus the normal umbilical cord consists of two UAs and one UV. While a persistent four-vessel umbilical cord rarely occurs [30], the most common cord variant, with an incidence of approx. $0.5 \%$ in the second trimester [31], is a single UA (two vessels: one vein and only one artery; SUA = single umbilical artery). Visualisation of the umbilical arteries is done either in the free umbilical cord or preferably at the level of the fetal urinary bladder by demonstrating the cord's perivesical course using colour Doppler ultrasound ( Fig. 7).

Using colour Doppler and high definition ultrasound, SUA can be diagnosed at this level as early as the first trimester. A low pulse repetition frequency (PRF) and a high colour gain are recommended, as comparatively small vessels (compared to the opposite side) may otherwise be overlooked ( Fig. 7c and d). The perivesical course of the UAs should be visualised all the way to the umbilicus as there is a danger of confusion with fetal femoral arteries in early gestation ( Fig. $\mathbf{8 c}$ and $\mathbf{d}$ ).

If single umbilical artery is suspected in the first trimester the diagnosis should be confirmed at a later stage ( $\bullet$ Fig. $\mathbf{8} \mathbf{a}$ and $\mathbf{b}$ ). The existing (single) UA compensates and its lumen is usually bigger than that of a three-vessel cord, with a diameter ratio of UV/UA $\leq 2$ (in three-vessel cord UV/UA the ratio is $>2$ ) [32]. The main clinical relevance of SUA is the association with structural abnormalities of the fetal cardiovascular and genitourinary systems, as well as more rare gastrointestinal and CNS abnormalities [11]. Approximately one third of fetuses with SUA have structural abnormalities, and chromosomal anomalies are found in 10\% [31], although according to current data isolated occurrence of SUA does not significantly increase the risk of chromosomal anomalies [31,33]. SUA is regarded as a marker for the development of fetal growth restriction and premature birth [34].

The demonstration of an SUA should always prompt a detailed anatomical ultrasound examination with particular focus on the cardiovascular and genitourinary systems. Increased pregnancy monitoring because of the higher risk of IUGR is currently controversial [11,31].

\section{The Second Trimester \\ $\nabla$}

Assessment of the UC in the second trimester can be difficult due to fetal interference when the placenta is posterior, or a convoluted cord. However, because of fetal growth, the now larger individual vessels are easier to assess. Thus SUA is often first diagnosed in the second trimester. Structural changes of the umbilical vein are also mostly diagnosed in the second trimester.

\section{Structural changes of the umbilical vein}

There are two structural UV variants which are of clinical importance, both involving its intraabdominal course.

\section{Persistent right umbilical vein (PRUV)}

By the 7th week of gestation one of the initially paired UVs (usually the right one) has typically atrophied. The left UV initially runs dorsally in the abdomen and joins the portal system. In abdominal transverse section (at a level slightly caudal of the biometry level) the umbilicoportal vessels arch to the right appearing to "encircle" the gallbladder while passing the stomach tangentially ( Fig. 9a).

Portal vessels branch off along its course, as does the ductus venosus approximately at the peak of the dorsal arch ( $\odot$ Fig. $\mathbf{9 b}$ ). Chaoui et al. recently published a detailed description of the hepatic veins as a CME article in German and English [35]. 

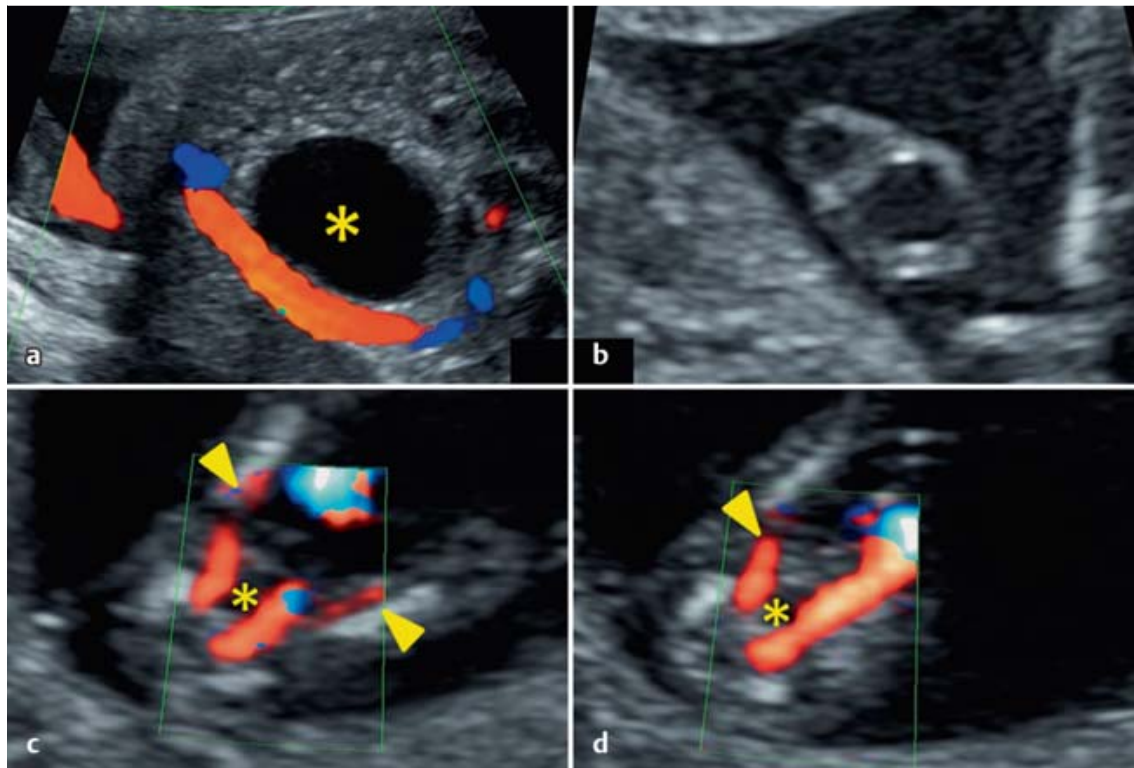

Fig. 8 a to $\mathbf{d}$ Single umbilical artery.

$\mathbf{a}$ and $\mathbf{b}$ SUA in the second trimester- perivesical (a) and in cross section (b).

c and $\mathbf{d}$ SUA in the first trimester, perivesical - a low pulse repetition frequency and high colour gain are recommended to assist in differentiating vessels from the nearby femoral arteries $(\downarrow)$ ) (vessel course all the way to the fetal cord insertion - for comparison, see also $\odot$ Fig. $7 \mathrm{c}$ und $\mathbf{d})$. Caption: urinary bladder $\left({ }^{*}\right)$.
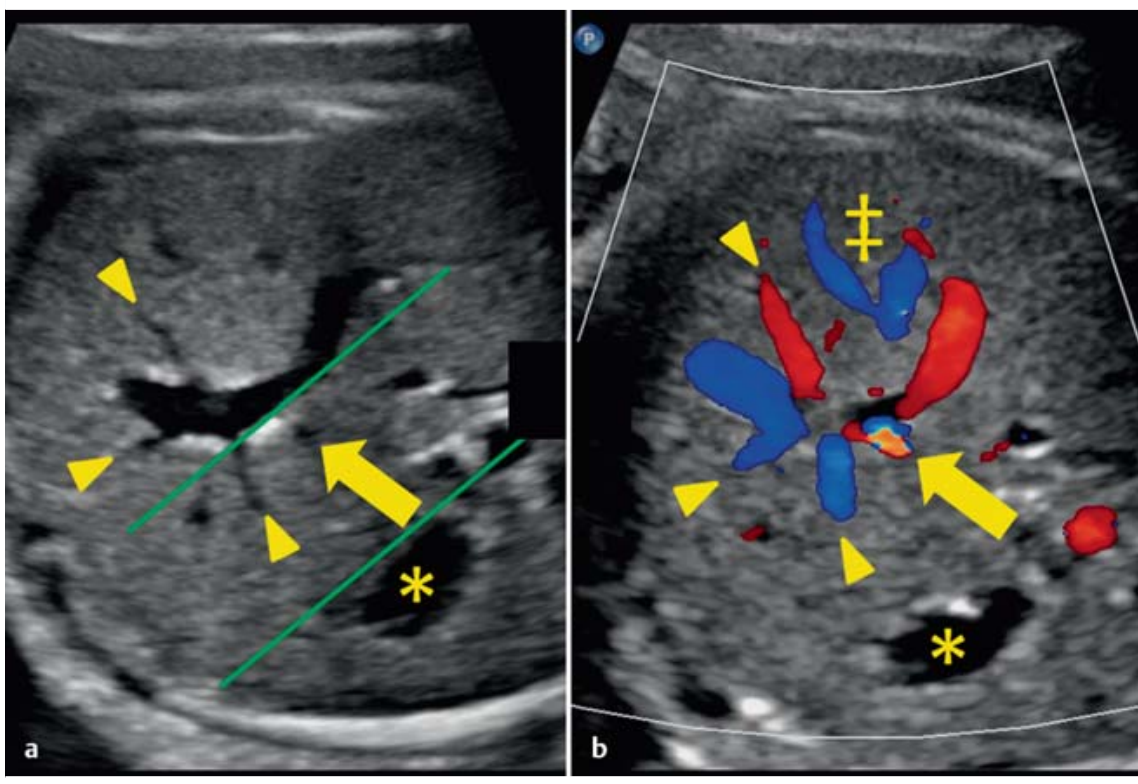

Fig. 9a and b Normal anatomy: intrabdominal course of the UV and union with portal system. Green lines in section a show the tangential course of the arching vessel with respect to the fetal stomach $\left({ }^{*}\right)$. The left portal vein branch $(\boldsymbol{})$ and ductus venosus $(\rightarrow)$ are visible. In section $\mathbf{b}$ a colour change allows identification of the ductus venosus ("aliasing" caused by flow acceleration). Caption: hepatic veins ( $\ddagger$ ).
If the left UV atrophies, the right UV persists (PRUV). The incidence is reported to be around $0.5-3: 1000[11,36]$. In ideal imaging circumstances the ultrasound shows a mirror image course of the vessel arching left towards the stomach. The gallbladder lies medially and thus also within the vascular arch. Demonstration as in 0 Fig. $\mathbf{1 0}$ is usually more difficult since the gallbladder is more caudal to the UV.

Persistent right umbilical vein should be regarded as a normal variant of no clinical significance when it connects to the portal system intrahepatically (intrahepatic variant of PRUV giving rise to the ductus venosus). However, during embryonic development, extrahepatic communications between the UVs and the sinus venosus (later communicating with the right atrium) develop, which later obliterate while an anastomosis between one of the UVs and the sinusoids of the liver develops [36]. If the right UV persists it is more common for this anastomosis not to take place, with the extrahepatic connection to the right atrium remaining patent (without development of the ductus venosus).
This extrahepatic connection causes an increased preload as the entire umbilical venous blood volume bypasses the liver to enter the right atrium directly. Significant right heart strain and subsequent hydrops fetalis can develop. Thus if a PRUV is diagnosed, further cardiovascular anomalies should be excluded. The clinical approach is dictated if concurrent malformations are present. Where PRUV is isolated, and an intrahepatic connection to the portal system exists, the prognosis is excellent [36].

\section{Umbilical vein varix}

Dilation of the UV in its extrahepatic course behind the fetal cord insertion is diagnosed with an incidence of $2.8: 1000$ and is termed umbilical vein varix [37]. Morphologically on ultrasound a circular vessel dilation $\geq 9 \mathrm{~mm}$ [38] or more than $50 \%$ over the diameter of the intrahepatic UV is seen [39] ( Fig. 11).

Due to its association with chromosomal anomalies (especially trisomy 21) and other abnormalities, if umbilical vein varix is diagnosed, further focused examination of the fetus should always 

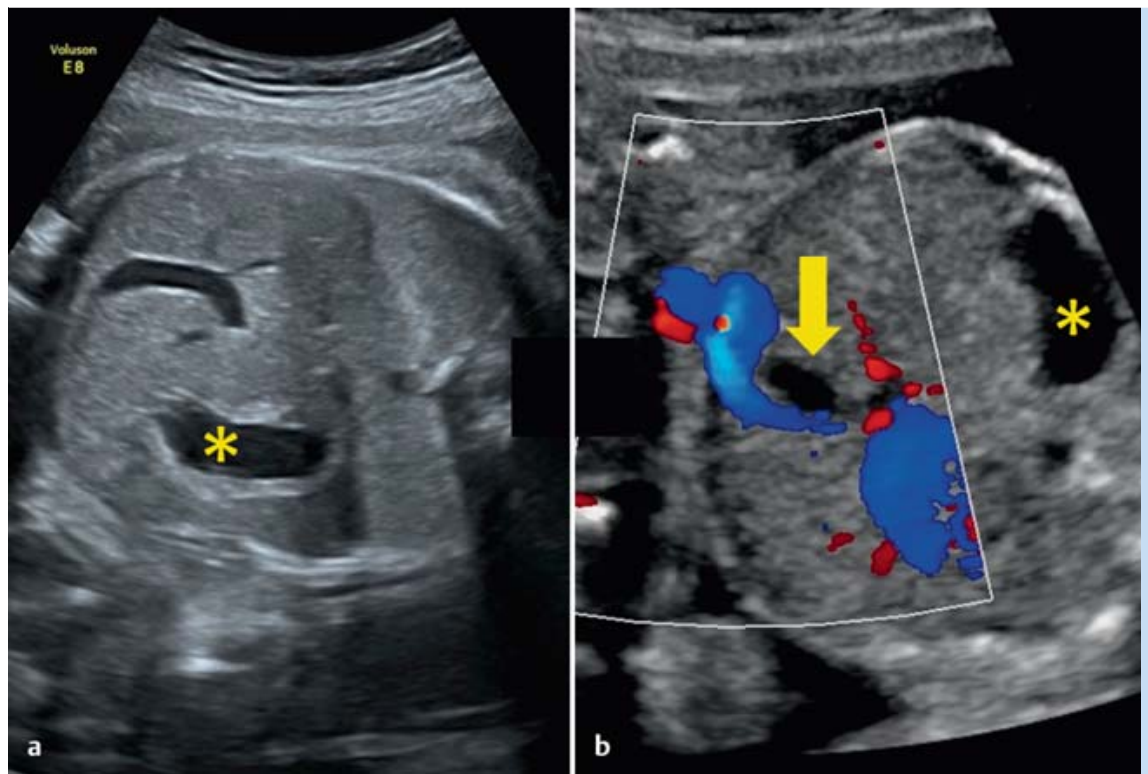

Fig. $10 \mathbf{a}$ and $\mathbf{b}$ Persistent right umbilical vein (PRUV). The vascular arch runs towards the stomach (see $\bullet$ Fig. 9 for comparison). The gallbladder $(\rightarrow)$ lies medially to the right UV. Caption: stomach $\left({ }^{*}\right)$.
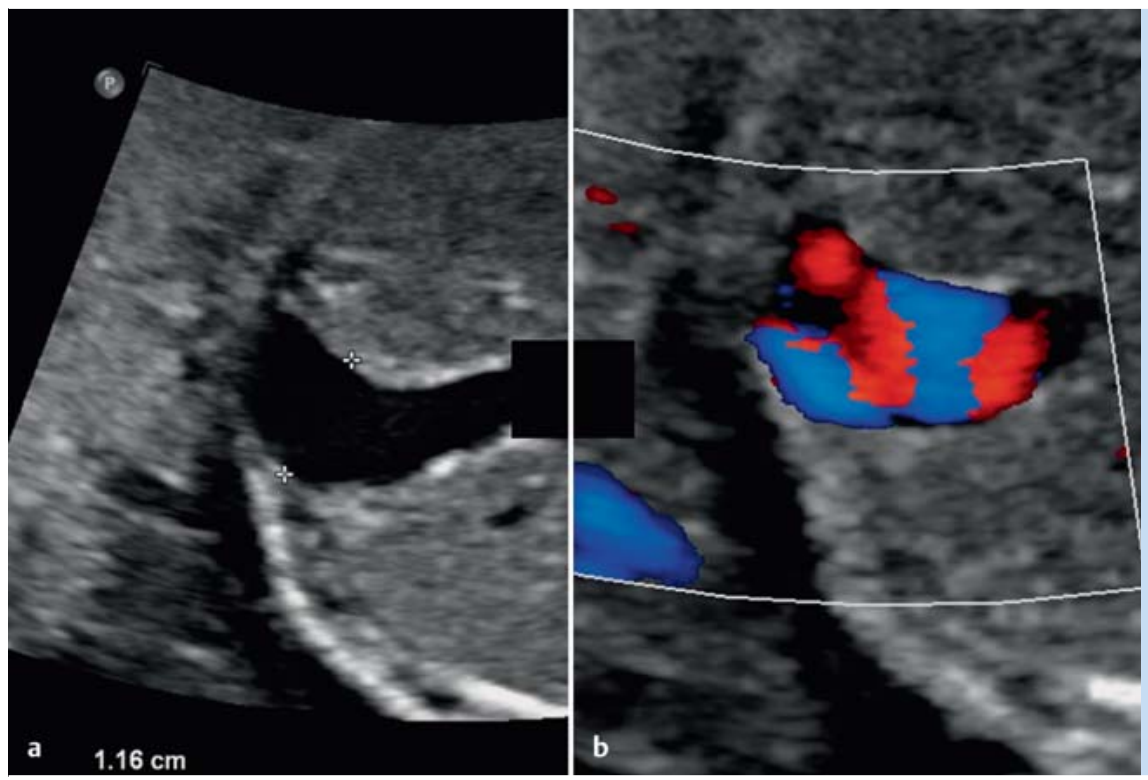

Fig. 11 a and $\mathbf{b}$ Umbilical vein varix with a diameter of $11.6 \mathrm{~mm}$. Turbulent flow within the outpouching/vessel dilatation is shown on Doppler ultrasound.

be done $[37,40]$. Increased rates of IUGR and intrauterine death have also been described. The optimal timing of delivery (recommendations start from 34 completed weeks of gestation) is currently controversial since cases of intrauterine death have been described despite intensified monitoring even in the presence of isolated umbilical vein varix $[41,42]$.

\section{The Third Trimester}

$\nabla$

Umbilical cord loops and prolapse

Umbilical cord loops (the UC is wrapped at least once around the fetus's neck, more rarely around the body) are increasingly common as gestational age increases with an incidence of up to $33 \%$ at term [43]. Although in most cases UC loops have no negative effect on perinatal outcome, the possibility of higher rates of UC compression as a cause of fetal distress or even asphyxia and intrauterine death is currently discussed. Although some of the above-mentioned UC complications are existentially relevant, current data do not show increased risk in the presence of less than 3 loops [43]. Nevertheless the diagnosis often triggers significant uncertainty and anxiety in pregnant patients and this must be taken into account when counselling the patient.

A unique form of UC loop occurs in monoamniotic twin pregnancies ( Fig. 12). Since both fetuses are freely mobile in their common amniotic cavity, UC loops, knots and a thoroughly convoluted/tangled cord is the rule [44]. There is currently no consensus on optimal antenatal monitoring or timing of delivery of monoamniotic twins, which are generally high risk (mortality $8-42 \%$ [44]). The finding of a convoluted UC in monoamniotic twin pregnancies does not appear to have a significant effect on overall risk [45].

The term umbilical cord prolapse describes when the UC, as the presenting part, prolapses into the cervix or vagina after rupture of membranes. This must be distinguished from cord presentation outside of labour. UC prolapse has a mortality of up to $50 \%$ 

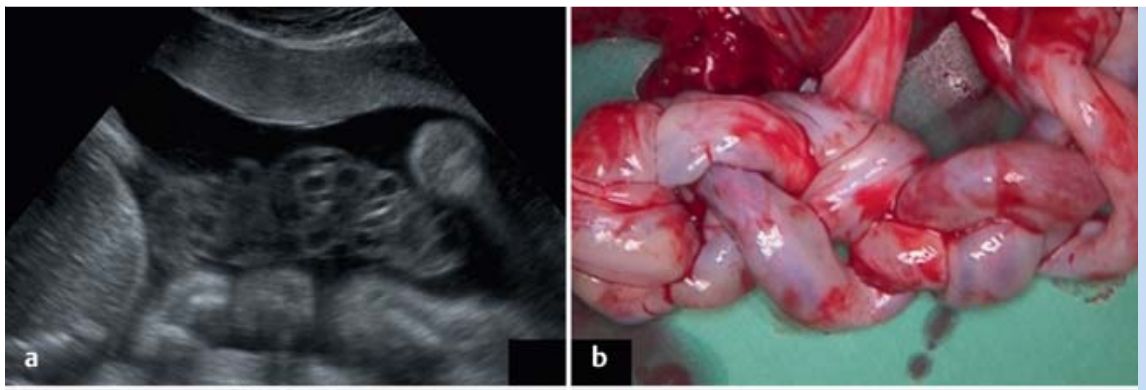

Fig. 12 a to $\mathbf{d}$ Convoluted umbilical cord in a monoamniotic twin pregnancy.

a Demonstration on ultrasound.

b Macroscopic view of tangled umbilical cords.

c and $\mathbf{d}$ Doppler ultrasound assessment of tangled umbilical cords. Two independent curves are seen in parallel (fetus 1 and fetus 2).
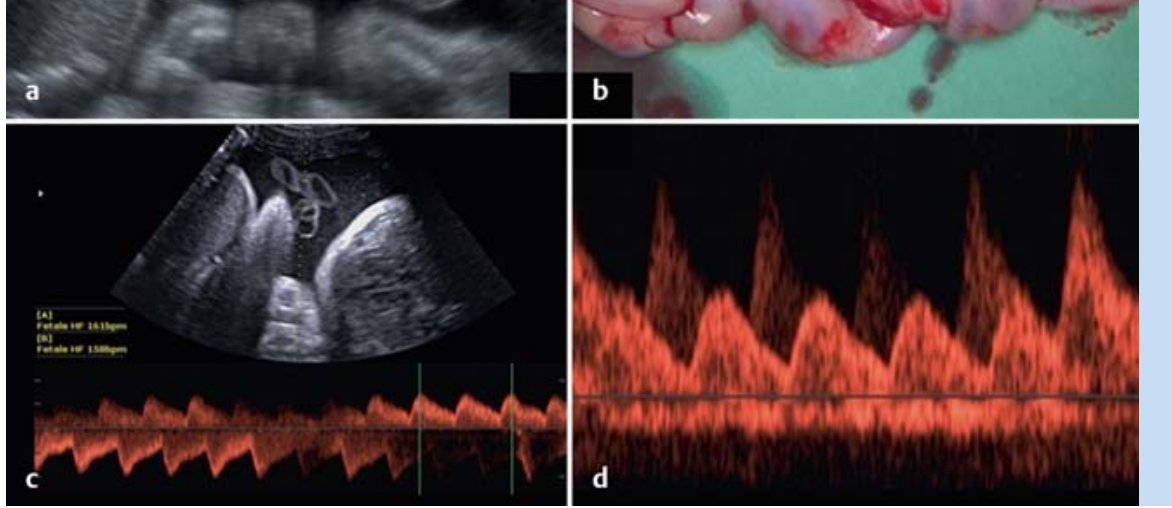

[11], although current data show a reduction in mortality to under $10 \%$ in the context of rising caesarean section rates [46].

The main risk factor for cord prolapse necessitating emergent delivery, is abnormal fetal lie. Numerous other factors are also associated with increased risk including prematurity and low birth weight, abnormalities of the maternal pelvis, polyhydramnios, UC length $>80 \mathrm{~cm}$ and others (male sex, multiple pregnancy, placenta praevia and obstetric interventions) [46].

Risk factors such as multiple cord loops, very low placental cord insertion or polyhydramnios should be known to the obstetric team as this knowledge is essential for the correct interpretation of the progress of labour and particularly the CTG performed during labour, with labour management adjusted to take account of this information.

\section{True and false knots}

Umbilical cord compression can also be caused by tightening of a true UC knot. So-called false knots, in contrast, are varicose dilatations of umbilical vessels with an appearance sometimes imitating true knots. Their course is snaked but the UC does not form an actual knot that can tighten. UC knots are usually diagnosed postnatally. Antenatal diagnosis of true knots is possible, also causing major maternal anxiety. Well-defined diagnostic criteria and management standards are currently lacking and misdiagnosis is relatively common. Nevertheless, diagnosis of a UC knot should be followed by detailed Doppler ultrasound of the UC and stringent pregnancy monitoring $[47,48]$.

\section{Umbilical cord tumours}

Umbilical cord tumours are very rare entities. In most cases they are haemangiomas or teratomas. As in the case of UC haematomas (see below), tumours can cause umbilical vessel compression. Antenatally haemangiomas appear as echogenic structures with demonstrable perfusion on Doppler ultrasound. Multicystic variants make the differentiation from teratomas and haematomas particularly difficult [11]. Mortality is estimated to be $40 \%$. Associated fetal malformations are described without any specific preponderance [49].

Teratomas of the UC are usually benign tumours. Their appearance on ultrasound is heterogeneous often with both cystic and solid components. Concurrent malformations are described in about half of published cases. Teratomas can reach considerable size and are a cause of cardiac failure in the fetus ("high-output heart failure"). Rupture of cord vessels is a particular danger associated with UC teratomas [50].

\section{Special Considerations}

$\nabla$

\section{Doppler ultrasound}

Doppler ultrasound of the UC is relatively easy to carry out even in the later weeks of pregnancy thanks to the length and variable course of the UC. Due to the flexibility of the cord, vessels can usually be examined at the appropriate angle for good quality spectral curves. Nevertheless the cord's length and winding course make standardisation and the exact definition of the examined segment and precise Doppler measurement at a specific angle difficult.

The umbilical arteries are the most commonly examined vessels in the assessment of fetal circulation. They provide information on the fetoplacental capillary bed; where resistance is increased, investigation of the UAs allows early detection of risk to the fetus. Assessment of UC blood flow is done particularly in the setting of fetal growth restriction to differentiate between compensated and decompensated placental insufficiency. Various (semi-) quantitative and qualitative measures can be assessed. The umbilical vein also provides information on the fetal status, allowing assessment of the fetal central venous vasculature, e.g. increased preload in the setting of right heart failure. The examination of other fetal and/or maternal vessels is often necessary for a complete assessment. We refer the reader to textbooks on the application of Doppler ultrasound in obstetrics for a complete description of Doppler ultrasound of the UC.

\section{Invasive procedures and umbilical cord haematoma}

Fetal blood sampling for the investigation of fetal anaemia, congenital infections and specialised genetic investigations is possible through UC puncture. Ultrasound-guided puncture of the UV allows both blood sampling and, via the same route, blood transfusion for the correction of fetal anaemia as indicated. The proce- 
dural risk of abortion is $1 \%$ (fetus without malformations) [51]. A very rare complication is the development of a UC haematoma that, if large enough, can compress UC vessels and impair fetal circulation [52]. Spontaneous formation of a haematoma is also possible and the following risk factors have been reported: short UC, cord prolapse, velamentous cord insertion [53] and fetal clotting disorders [54]. UC haematomas are associated with a high rate of asphyxia and fetal mortality.

\section{Conclusion}

Detailed examination of the umbilical cord provides information on different aspects of fetal development. Targeted examination should be undertaken in early pregnancy as many details of cord development become increasingly difficult to demonstrate on ultrasound with increasing gestational age. The detection of abnormalities in the number, structure or course of cord vessels should prompt further extended investigation since associations with other structural (especially cardiovascular) and chromosomal anomalies exist. Isolated abnormalities of the cord mostly carry a favourable prognosis. Particular attention should be paid to fetal and placental umbilical cord insertions.

\section{Conflict of Interest}

\section{$\nabla$}

None.

\section{References}

1 Ferguson VL, Dodson RB. Bioengineering aspects of the umbilical cord. Eur J Obstet Gynecol Reprod Biol 2009; 144 (Suppl. 1): S108-S113

2 Raio L, Ghezzi F, Di Naro E et al. Sonographic measurement of the umbilical cord and fetal anthropometric parameters. Eur J Obstet Gynecol Reprod Biol 1999; 83: 131-135

3 Gordon Z, Eytan O, Jaffa AJ et al. Hemodynamic analysis of Hyrtl anastomosis in human placenta. Am J Physiol Regul Integr Comp Physiol 2007; 292: R977-R982

4 Bhutia KL, Sengupta R, Upreti B et al. Pregnancy-induced hypertension is associated with altered anatomical patterns of Hyrtl's anastomosis. Anat Rec (Hoboken) 2014; 297: 819-825

5 Raio L, Ghezzi F, di Naro $E$ et al. In-utero characterization of the blood flow in the Hyrtl anastomosis. Placenta 2001; 22: 597-601

6 Raio L, Ghezzi F, Di Naro E et al. Prenatal assessment of the Hyrtl anastomosis and evaluation of its function: case report. Hum Reprod 1999; 14: $1890-1893$

7 Strong TH jr., Jarles DL, Vega JS et al. The umbilical coiling index. Am J Obstet Gynecol 1994; 170: 29-32

8 Mittal A, Nanda S, Sen J. Antenatal umbilical coiling index as a predictor of perinatal outcome. Arch Gynecol Obstet 2015; 291: 763-768

9 Narayan $R$, Saaid $R$, Pedersen $L$ et al. Ultrasound assessment of umbilical cord morphology in the first trimester: a feasibility study. Fetal Diagn Ther 2015; [Epub ahead of print]

10 Verkleij CP, van Oppen AC, Mulder EJ et al. Evaluation of antenatal umbilical coiling index at 16-21 weeks of gestation as a predictor of trisomy 21 and other chromosomal defects. Ultrasound Obstet Gynecol 2013; 42: 545-552

11 Moshiri M, Zaidi SF, Robinson TJ et al. Comprehensive imaging review of abnormalities of the umbilical cord. Radiographics 2014; 34: 179-196

12 Jessop FA, Lees CC, Pathak $S$ et al. Umbilical cord coiling: clinical outcomes in an unselected population and systematic review. Virchows Arch 2014; 464: 105-112

13 Rayburn WF, Beynen A, Brinkman DL. Umbilical cord length and intrapartum complications. Obstet Gynecol 1981; 57: 450-452

14 Hill LM, DiNofrio DM, Guzick D. Sonographic determination of first trimester umbilical cord length. J Clin Ultrasound 1994; 22: 435-438

15 Murphy A, Platt $L D$. First-trimester diagnosis of body stalk anomaly using 2- and 3-dimensional sonography. J Ultrasound Med 2011; 30: $1739-1743$
16 Prefumo F, Izzi C. Fetal abdominal wall defects. Best Pract Res Clin Obstet Gynaecol 2014; 28: 391-402

17 Smrcek JM, Germer U, Krokowski M et al. Prenatal ultrasound diagnosis and management of body stalk anomaly: analysis of nine singleton and two multiple pregnancies. Ultrasound Obstet Gynecol 2003; 21: 322328

18 Ugurlucan FG, Yuksel A. Is complete umbilical cord scanning possible at the second-trimester ultrasound scan? J Clin Ultrasound 2014; DOI: $10.1002 /$ jcu. 22242

19 Hasegawa J, Matsuoka R, Ichizuka $\mathrm{K}$ et al. Ultrasound diagnosis and management of umbilical cord abnormalities. Taiwan J Obstet Gynecol 2009; 48: 23-27

20 Oyelese Y, Catanzarite V, Prefumo F et al. Vasa previa: the impact of prenatal diagnosis on outcomes. Obstet Gynecol 2004; 103: 937-942

21 Rao KP, Belogolovkin V, Yankowitz J et al. Abnormal placentation: evidence-based diagnosis and management of placenta previa, placenta accreta, and vasa previa. Obstet Gynecol Surv 2012; 67: 503-519

22 Oyelese Y, Smulian JC. Placenta previa, placenta accreta, and vasa previa. Obstet Gynecol 2006; 107: 927-941

23 Gagnon R, Morin L, Bly $S$ et al. SOGC CLINICAL PRACTICE GUIDELINE: guidelines for the management of vasa previa. Int J Gynaecol Obstet 2010; 108: 85-89

24 Ruiter L, Kok N, Limpens J et al. Systematic review of accuracy of ultrasound in the diagnosis of vasa previa. Ultrasound Obstet Gynecol 2015; 45: $516-522$

25 Rebarber A, Dolin C, Fox NS et al. Natural history of vasa previa across gestation using a screening protocol. J Ultrasound Med 2014; 33: $141-147$

26 Mastroiacovo P, Lisi A, Castilla EE et al. Gastroschisis and associated defects: an international study. Am J Med Genet A 2007; 143A: 660-671

27 Bonilla F jr., Raga F, Villalaiz E et al. Umbilical cord cysts: evaluation with different 3-dimensional sonographic modes. J Ultrasound Med 2010; 29: 281-285

28 Zangen R, Boldes R, Yaffe $H$ et al. Umbilical cord cysts in the second and third trimesters: significance and prenatal approach. Ultrasound Obstet Gynecol 2010; 36: 296-301

29 Hannaford K, Reeves S, Wegner E. Umbilical cord cysts in the first trimester: are they associated with pregnancy complications? J Ultrasound Med 2013; 32: 801-806

30 Avnet $H$, Shen 0, Mazaki $E$ et al. Four-vessel umbilical cord. Ultrasound Obstet Gynecol 2011; 38: 604-606

31 Voskamp BJ, Fleurke-Rozema H, Oude-Rengerink K et al. Relationship of isolated single umbilical artery to fetal growth, aneuploidy and perinatal mortality: systematic review and meta-analysis. Ultrasound Obstet Gynecol 2013; 42: 622-628

32 Sepulveda W, Peek MJ, Hassan J et al. Umbilical vein to artery ratio in fetuses with single umbilical artery. Ultrasound Obstet Gynecol 1996; 8: 23-26

33 Dagklis T, Defigueiredo D, Staboulidou I et al. Isolated single umbilical artery and fetal karyotype. Ultrasound Obstet Gynecol 2010; 36: 291295

34 Mailath-Pokorny $M$, Worda $K$, Schmid $M$ et al. Isolated single umbilical artery: evaluating the risk of adverse pregnancy outcome. Eur J Obstet Gynecol Reprod Biol 2015; 184: 80-83

35 Chaoui R, Heling KS, Karl K. Ultrasound of the fetal veins part 1: the intrahepatic venous system. Ultraschall Med 2014; 35: 208-228

36 Weichert J, Hartge D, Germer $U$ et al. Persistent right umbilical vein: a prenatal condition worth mentioning? Ultrasound Obstet Gynecol 2011; 37: 543-548

37 Lee SW, Kim MY, Kim JE et al. Clinical characteristics and outcomes of antenatal fetal intra-abdominal umbilical vein varix detection. Obstet Gynecol Sci 2014; 57: 181-186

38 Allen SL, Bagnall C, Roberts AB et al. Thrombosing umbilical vein varix. J Ultrasound Med 1998; 17: 189-192

39 Sepulveda W, Mackenna A, Sanchez J et al. Fetal prognosis in varix of the intrafetal umbilical vein. J Ultrasound Med 1998; 17: 171-175

40 Byers BD, Goharkhay N, Mateus J et al. Pregnancy outcome after ultrasound diagnosis of fetal intra-abdominal umbilical vein varix. Ultrasound Obstet Gynecol 2009; 33: 282-286

41 Zalel Y, Lehavi 0 , Heifetz $S$ et al. Varix of the fetal intra-abdominal umbilical vein: prenatal sonographic diagnosis and suggested in utero management. Ultrasound Obstet Gynecol 2000; 16: 476-478

42 Valsky DV, Rosenak D, Hochner-Celnikier D et al. Adverse outcome of isolated fetal intra-abdominal umbilical vein varix despite close monitoring. Prenat Diagn 2004; 24: 451-454 
43 Kong CW, Chan LW, To WW. Neonatal outcome and mode of delivery in the presence of nuchal cord loops: implications on patient counselling and the mode of delivery. Arch Gynecol Obstet 2015; 292: 283-289

44 Dias T, Mahsud-Dornan S, Bhide A et al. Cord entanglement and perinatal outcome in monoamniotic twin pregnancies. Ultrasound Obstet Gynecol 2010; 35: 201-204

45 Rossi AC, Prefumo F. Impact of cord entanglement on perinatal outcome of monoamniotic twins: a systematic review of the literature. Ultrasound Obstet Gynecol 2013; 41:131-135

46 Lin MG. Umbilical cord prolapse. Obstet Gynecol Surv 2006; 61: 269277

47 Hasbun J, Alcalde JL, Sepulveda W. Three-dimensional power Doppler sonography in the prenatal diagnosis of a true knot of the umbilical cord: value and limitations. J Ultrasound Med 2007; 26: 1215-1220

48 Abuhamad A. Three-dimensional ultrasound with color Doppler imaging of an umbilical cord true knot. Ultrasound Obstet Gynecol 2014; 43: 360
49 Sathiyathasan S, Jeyanthan K, Hamid R. Umbilical hemangioma: a case report. Arch Gynecol Obstet 2011; 283 (Suppl. 1): 15-17

50 Satge DC, Laumond MA, Desfarges F et al. An umbilical cord teratoma in a 17-week-old fetus. Prenat Diagn 2001; 21: 284-288

51 Berry SM, Stone J, Norton ME et al. Fetal blood sampling. Am J Obstet Gynecol 2013; 209: 170-180

52 Tongsong T, Wanapirak C, Kunavikatikul C et al. Cordocentesis at 16-24 weeks of gestation: experience of 1,320 cases. Prenat Diagn 2000; 20: 224-228

53 Seoud M, Aboul-Hosn L, Nassar A et al. Spontaneous umbilical cord hematoma: a rare cause of acute fetal distress. Am J Perinatol 2001; 18 : 99-102

54 Jouannelle C, Giansily-Blaizot M, Monpoux F et al. Spontaneous umbilical cord haematoma and congenital factor VII deficiency. Haemophilia 2012; 18: e24-e25 